\title{
Integrating information on marine species identification for fishery purposes
}

\author{
Jordi Lleonart*, Marc Taconet, Michel Lamboeuf
}

FAO Fisheries Department, Viale delle Terme di Caracalla, 00100 Rome, Italy

\begin{abstract}
Species identification for fishery purposes has been the subject of a major Food and Agriculture Organization (FAO) program since the 1960s. One of the main objectives is to improve catch statistics through accurate species identification. A number of guides (geographical), catalogues (taxonomic) and species synopses have been produced as hard copy, and, more recently, most of these publications have become freely available on the Internet. Species fact sheets are a new electronic product with a database structure integrated in the Fisheries Global Information System (FIGIS). FIGIS interconnects species information with many other types of information related to fisheries (statistics, stocks inventories and assessment reports, fisheries inventories, fishing techniques, fisheries management systems, introduced species, cultured species etc.) and with a wide range of services available from other FAO systems (virtual document library, mapping library, legislation library, scientific abstracts). FIGIS achieves these features thanks to a flexible 3-tier architecture based on open-source software (Java, XML, XSL, HTML), a metadata framework based on international standards, formal institutional partnerships for information sharing, and the exploitation and display of web services. Several gaps in geographical and taxonomical coverage have been determined; these are mainly located in South America and concern several taxa (particularly crustaceans) and some fish families of paramount importance to fisheries. Other species identification tools to address multispecies and ecosystem modeling are also needed. Finally, optimization of the worldwide community efforts in generating and sharing taxonomically related knowledge in a global network is a current challenge calling for an urgent solution.
\end{abstract}

KEY WORDS: FAO $\cdot$ Species identification $\cdot$ Databases

\section{INTRODUCTION}

The Food and Agriculture Organization (FAO) of the United Nations (UN) leads international efforts in defeating hunger. Serving both developed and developing countries, the FAO is also a major source of knowledge and information. It helps developing countries and countries in transition to modernize and improve agriculture, forestry and fishery practices and to ensure good nutrition for all. The mission of the Fisheries Department of the FAO is to facilitate and secure the long-term sustainable development and utilization of the world's fisheries and aquaculture resources.

Species identification is a major fisheries issue, which has been recognized since the 1960s. The preamble of the very first species identification guide (Fischer 1973) states, 'It is hoped that the use of this new work tool will contribute to the improvement of national and regional fishery statistics and will facilitate fishery resources survey work, sampling schemes and fishery activities in general.'

The Species Identification and Data Program (SIDP) was initiated in the early 1970s to improve the quality of fisheries data collection by species through reliable species identifications in the field, in particular in developing areas and countries. Nowadays, this objective also serves the requirements of the code of conduct for responsible fisheries (FAO 1995), which provides a new framework to integrate information on biodiversity, species introductions and protection of endangered species. Hence, not only commercial spe- 
cies are the subject of species identification publications, but also species with indirect relevance to fisheries, such as marine mammals or turtles.

When the 1995 code of conduct for responsible fisheries was approved as a basis for policies aimed at sustainable fisheries, a major need for reliable, high-quality and relevant information on world fisheries was identified. In 1999, the Fisheries Department launched the development of a global network of integrated fisheries information (FIGIS-Fisheries Global Information System; www.fao.org/fi/figis) to address this need.

FIGIS is an information management tool designed (1) to promote policy change towards the sustainable use of the world's fishery resources by highlighting major issues, presenting possible solutions and providing the best scientific information available, (2) to offer a single and unique entry point to strategic data, information, analyses and reviews of issues and trends on a broad range of fisheries subjects and (3) to provide quality-controlled, harmonized, streamlined and comprehensive information. FIGIS, as an information management tool, interconnects a network of subsystems, some of which are made accessible through partnership arrangements with other institutions.

\section{NECESSITY TO IMPROVE SPECIES IDENTIFICATION AND FISHERY STATISTICS}

Correct identification to the species level is necessary for most biological studies; however, higher taxonomic levels have also been used in ecological and fisheries analyses (Myers \& Worm 2003, Pauly et al. 2003). Taxonomy is facing a prestige crisis (Godfray 2002), and the obvious connection between the increasing concern about declining biodiversity and the need for species identification is not always recognized (Boero 2001).

One of the key problems that makes fisheries management difficult is the erroneous and/or imprecise identification of the exploited species. This leads to an ill-defined or inappropriate species catch attribution, evidenced by the significant quantities of catches that are reported only in higher taxonomic level groupings in the statistics. Every year, countries are requested to provide the FAO with their catch statistics by species and fishing areas. The FISHSTAT Plus Capture production database contains catch data since 1950 (FAO 2004). It includes 1347 'species items' (actual species or groups of species). It should be noted that the number of species items has grown continuously, i.e. in 1990 the number of items was 995 (L. Garibaldi pers. comm.). For the purpose of this study the items have been divided into 4 levels of taxonomic groups: (1) species, e.g. Sardina pilchardus; (2) genus, e.g.
Table 1. Taxonomic aggregation of average world catch data (in metric tons) from 1950 to 2002. HTG: higher taxonomic groups; SI: species items

\begin{tabular}{|lrrcr|}
\hline & SI & Tons & Percent of catch & Tons SI \\
\hline Species & 1008 & 42785479 & 66.45 & 42446 \\
Genus & 180 & 5485170 & 8.52 & 30473 \\
Family & 109 & 2554751 & 3.97 & 23438 \\
HTG & 50 & 13557787 & 21.06 & 271156 \\
Total & 47797 & 96292408 & & 71487 \\
\hline
\end{tabular}

Dentex spp.; (3) family, e.g. Congridae; and (4) higher taxonomic groups (HTG), e.g. Gadiformes, Bivalvia, Osteichthyes.

In 2002 , more than $60 \%$ of the catch was attributed to 1008 single, identified species, but more than $20 \%$ of the catch was included in the too general HTG category (Table 1), attributed to only 50 items. Caddy \& Garibaldi (2000) found that $65.9 \%$ of the total capture production reported to the FAO for 1996 was at the species level, but also observed a great difference between temperate areas, with $90 \%$ at the species level, and tropical areas, where it was often lower than $40 \%$.

A study of the historical series of world capture fishery production statistics shows that species resolution is declining. The number of catches reported at the species level is decreasing, while the trend for reports of aggregated groups is increasing (Fig. 1); these trends are statistically significant in all cases (Table 2). An important source of imprecision lies in the statistics of some SE Asian countries. For example, data from China, Vietnam, Myanmar, Indonesia and eastern Thailand account for $62 \%$ of all the reported catch attributed to the HTG. After removing data from these countries, the $\%$ of HTG dropped, and the profile became even, with a nearly flat trend. With regard to species, the negative slope is attenuated, but still remains significant.

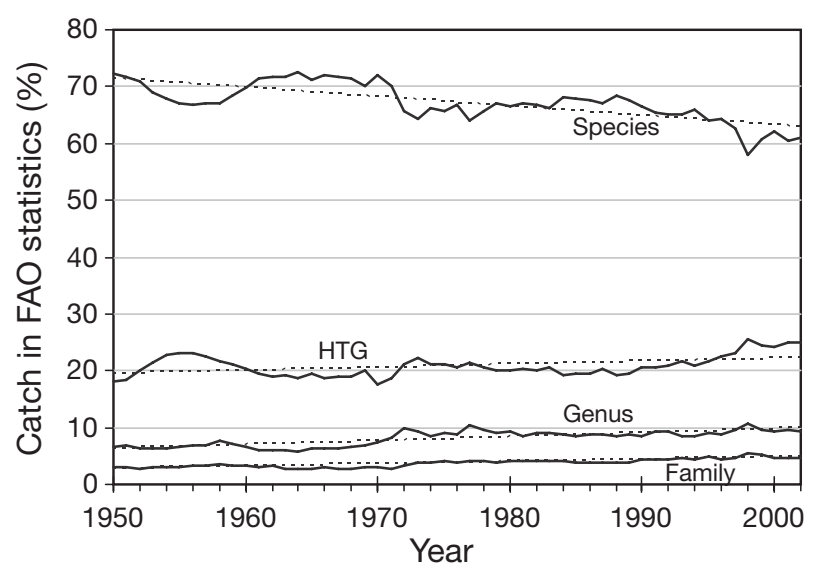

Fig. 1. Levels of catch identification in FAO statistics from 1950 to 2002 (solid lines: observed values; dotted lines: linear regressions; HTG: higher taxonomic groups) 
Table 2. Linear correlations between group allocation of catches for both annual and total catch. All values are significant (values higher than 0.27 are significant at $\alpha=0.05$ and $\mathrm{df}=51$ ). The linear correlation between annual and total catch is 0.9855

\begin{tabular}{|lrr|}
\hline & Annual & Total catch \\
\hline Species & -0.7442 & -0.6518 \\
Genus & 0.8053 & 0.7738 \\
Family & 0.8933 & 0.8264 \\
HTG & 0.4197 & 0.3004 \\
\hline
\end{tabular}

The decrease in capture fishery statistics species identification (with annual and/or total catch) is worrying. This can be attributed to an increase in catches grouped together as 'Osteichthyes, marine fishes nei' (nei = not elsewhere included), the number of which are constantly increasing, and to groups such as 'Crustacea' and 'Mollusca' that have increased in importance since 1990. However, some positive trends should be pointed out. For example, catches of 'sharks, rays and chimaeras' have been stable since 1996, at about 0.8 million metric tons, but the number of items reported at species level has increased from 45 to 95, indicating a remarkable improvement in species identification (FAO 2005). More generally, the continuous increase in the number of species items is also a positive indicator. Some regions have shown marked progress in species identification in the statistics, as in the eastern Central Atlantic, where the percentage of catches reported at species level increased from $43 \%$ in 1970 to $65 \%$ in 2002 , while HTG identifications dropped from 46 to $28 \%$ during the same period (CECAF 2004).

\section{FAO AND SPECIES IDENTIFICATION}

The objectives of the SIDP are (1) to improve the identification of marine organisms of actual and potential interest to fisheries; (2) to provide and disseminate tools to facilitate species identification in fisheries and, in so doing, improve fisheries data quality and (3) to provide a global and coherent system of scientific and common nomenclature. Priority is assigned to resources of major commercial importance that are considered threatened and to developing regions facing difficulties in species identification. SIDP relies on a network of $>100$ highly reputed taxonomists and scientists, each a specialist in his/her group, to process and validate the species identification information to be published.

SIDP produces 5 species identification collections, a large number of which are available at www.fao.org/ fi/sidp.

Regional guides. Comprehensive, coded, annotated and illustrated inventories of the species in some regions of the world are available. These include dichotomous identification keys and are based on contributions of a large group of taxonomists and fishery technicians. They are available as paper publications, and some are also available at the above website. So far, 8 such guides have been published (Table 3).

Field guides. Guides of commercial species containing fish landings for individual countries or groups of countries are also available. They are illustrationbased, with pictorial keys to families, a minimum of text and include common names. They are particularly aimed at national data collectors in need of quick identification of species in markets and landing places for the specific purpose of improving statistical and other fisheries data by species. So far 17 field guides have been published (Table 4). They are available as paper publications, and a few are also available at the SIDP website.

Catalogues. Worldwide inventories of taxonomic groups have been published. The scope of a catalogue is to deal with 1 or several taxonomic groups (class, order, family or subfamily) and to include all known species of the group around the world. They contain dichotomous identification keys: drawings, detailed descriptions, synonyms and world distribution. So far, 22 catalogues have been published. They are available both as paper publications and at the SIDP website The catalogues cover, partially or completely, 5 main

Table 3. List of regional guides

\begin{tabular}{|lll|}
\hline Editor(s) & Year & Region covered (publication language) \\
\hline W. Fischer \& P. J. P. Whitehead & 1974 & Eastern Indian Ocean and western Central Pacific (English) \\
W. Fischer, G. Bianchi \& W. B. Scott & 1981 & Eastern Central Atlantic (English \& French) \\
W. Fischer \& G. Bianchi & 1984 & Western Indian Ocean (English) \\
W. Fischer \& J. C. Hureau & 1985 & Southern Ocean (English, French \& Spanish) \\
W. Fischer, M.-L. Bauchot \& M. Schneider & 1987 & Mediterranean and Black Sea (French) \\
W. Fischer, F. Krupp, W. Schneider, C. Sommer, & 1995 & Eastern Central Pacific (Spanish) \\
K. E. Carpenter \& V. H. Niem & & \\
K. E. Carpenter \& V. H. Niem & 1998 & Western Central Pacific (English) \\
K. E. Carpenter & 2002 & Western Central Atlantic (English) \\
\hline
\end{tabular}


Table 4. List of field guides

\begin{tabular}{|c|c|c|}
\hline Author(s) & Year & Country covered (publication language) \\
\hline M.-L. Bauchot \& G. Bianchi & 1984 & Madagascar (French) \\
\hline G. Bianchi & 1985 & Pakistan (English) \\
\hline G. Bianchi & 1985 & Tanzania (English) \\
\hline G. Bianchi & 1986 & Angola (Portuguese) \\
\hline M. Bellemans, A. Sagna, W. Fischer \& N. Scialabba & 1988 & Senegal and Gambia (French) \\
\hline $\begin{array}{l}\text { W. Fischer, I. Sousa, C. Silva, A. De Freitas, } \\
\text { J.-M. Poutiers, W. Schneider, T. C. Borges, } \\
\text { J. P. Féral \& A. Massinga }\end{array}$ & 1990 & Moçambique (Portuguese) \\
\hline W. Schneider & 1990 & Gulf of Guinea (English \& French) \\
\hline D. H. Eccles & 1992 & Tanzania [freshwater] (English) \\
\hline $\begin{array}{l}\text { F. Cervigón, R. Cipriani, W. Fischer, L. Garibaldi, } \\
\text { M. Hendrickx, A. J. Lemus, R. Márquez, } \\
\text { J.-M. Poutiers, G. Robaina \& B. Rodriquez }\end{array}$ & 1993 & Northern coast of South American (English \& Spanish) \\
\hline G. H. P. De Bruin, B. C. Russell \& A. Bogusch & 1995 & Sri Lanka (English) \\
\hline W. J. Rainboth & 1996 & Cambodian Mekong (English) \\
\hline C. Sommer, W. Schneider \& J. M. Poutiers & 1996 & Somalia (English) \\
\hline K. E. Carpenter, F. Krupp, D. A. Jones \& U. Zajonz & 1997 & $\begin{array}{l}\text { Kuwait, eastern Saudi Arabia, Bahrain, } \\
\text { Qatar and the United Arab Emirates (English) }\end{array}$ \\
\hline D. Lloris \& J. Rucabado & 1998 & Morocco (French) \\
\hline $\begin{array}{l}\text { G. Bianchi, K. E. Carpenter, J.-P. Roux, F. J. Molloy, } \\
\text { D. Boyer \& H. J. Boyer }\end{array}$ & 1999 & Namibia (English) \\
\hline R. Bonfil \& M. Abdallah & 2004 & Sharks and rays of the Red Sea and Gulf of Aden (English) \\
\hline F. Serena & 2005 & Sharks and rays of the Mediterranean (English) \\
\hline
\end{tabular}

groups: fish, crustaceans, cephalopods, turtles and marine mammals. The catalogues published to date cover: shrimps and prawns, marine lobsters, cephalopods, marine turtles, marine mammals, sharks, and bony fish (Scombridae, Istiophoridae, Xiphiidae, Lutjanidae, Clupeoidei [Chirocentridae, Clupeidae, Pristigasteridae and Engraulidae], Caesionidae, Lethrinidae, Gadiformes, Nemipteridae, Sillaginidae, Gempylidae, Trichiuridae, Epinephelinae, Glaucosomatidae, Ophidiformes, Merlucciidae and Polynemidae).

Synopses. Synopses are comprehensive reviews of current knowledge on species of aquatic organisms of present or potential economic interest. Every synopsis covers all aspects of a single species: taxonomy, distribution, biology, fishery, utilization etc. They are available as paper publications, and a few are also available in electronic form.

Fact sheets on aquatic species. These are only available in electronic form through the SIDP website. The priorities for publishing species fact sheets are based on several criteria: species with a high level of world catch or a high revenue level, and those of importance with regard to biodiversity and conservation. At the end of 2004, 547 species fact sheets were available in FIGIS: 111 on sharks, 235 on bony fish, 42 on crustaceans, 9 on cephalopods, 24 on shells, 117 on mammals, 3 on turtles, 4 on algae, 1 on corals and 1 on sea urchins. Their dynamic generation and organization is further described in more detail.

\section{NEW INTERNET-BASED TECHNOLOGY FOR DISSEMINATION AND EXCHANGE OF SPECIES IDENTIFICATION}

It is not difficult nowadays to find more than 50 different websites on the Internet dealing with species identification on many levels, i.e. taxonomic (all groups, fish, cephalopods, crustaceans etc.), geographical area (worldwide or regional), special characteristics (e.g. invasive, endangered), use (e.g. aquariology, fisheries, aquaculture, SCUBA diving, food safety), parts of animals (e.g. otoliths), or life history (e.g. larvae). This reflects a great heterogeneity of data sources and products. However, only some of them can currently be recognized as references.

FishBase, a tremendously content-rich encyclopedia, is a much used source, although limited to fish in a taxonomic sense. The Integrated Taxonomic Information System (ITIS) appears to be the emerging webbased reference for standard taxonomic information on marine life (and more). Having online access to such a central register based on a commonly used taxonomic system across marine life, with an ever-increasing registry of living organisms managed under the Global Biodiversity Information Facility (GBIF), is essential to underpin biological databases and to enable webbased interoperability between information systems.

The Ocean Biogeographic Information System (OBIS) provides a good example of what a simple web-based 
system protocol can achieve in dynamically mapping species occurrence worldwide. This could be a tool of great interest for cross-checking and validating species distribution maps and, where data allow, generating some spatial index of probability of occurrence.

\section{THE FIGIS SYSTEM: AN ANSWER TO GROWING INFORMATION REQUIREMENTS}

Objectives. The role of FIGIS as an information tool is to support the FAO framework in its implementation of the Code of Conduct for Responsible Fisheries (CCRF; FAO 1995). The approach is fisheries-centered, with a focus on exploitation, usage and management of fishery resources. By offering a single entry point to comprehensive, reliable, high-quality and relevant information on the state of world fisheries, FIGIS should contribute to the promotion of policy changes towards the sustainable use of the world's fishery resources.

The various FAO fisheries programs (information and statistics, policy, resources, utilization and technology) have historically developed their own information bases to support their thematic analyses. FIGIS's primary objective was to consistently interconnect these databases. As a result, FIGIS currently handles 30 databases spread across 20 distinct information domains, such as statistics, aquatic species (SIDP fact sheets), introduced species, stocks, fisheries, management systems, institutions, laws, fishery country profiles, cultured species, glossaries, bibliographic references, news and events, etc., as well as standard classifications stored as reference data.

Content. The content of FIGIS should be understood as an information pyramid with various layers targeting distinct audiences. The top layer, aimed at policy makers, is presented in the form of policy notes, highlighting major fishery issues, presenting perspectives and possible solutions. Consistent with best practices as enshrined in international agreements, these policy notes and strategic summaries are systematically supported by the best scientific information available, thanks to links established to more technical information located in the lower layers of the information pyramid. Hence, at the base of the pyramid, FIGIS integrates detailed technical information of interest to analysts or scientists, such as fishery statistics, species identification, introduced species, fishing technology, description of geographical areas, of fishery management institutions, etc. In the middle of the pyramid, it facilitates the development of new information products, such as stocks or fisheries inventories, or dynamic country profiles. Responding to the best practices, these products enable users to trace source documents from global syntheses or reviews such as the Review of the state of world marine fishery resources (FAO 2005). Beyond its ability to integrate existing information bases, this middle layer constitutes the major novelty of FIGIS, as highlighted in the next section.

\section{NEW OPPORTUNITIES OFFERED BY FIGIS}

New databases for improved management of fishery resources. The newly developed marine resources and fisheries inventories databases well illustrate the role of FIGIS and the issues to which it responds: fishery statistics are generally highly aggregated and excessively based on catch or trade, resulting in minor fisheries being overlooked in policy making, despite the fact that collectively they can play a considerable role in the national economy and human livelihoods. An inventory of resources and fisheries would help to estimate the contribution of these poorly monitored fisheries and encourage policy-making to take into account the communities that depend upon these fisheries. The fisheries inventory also provides the backbone for linking other information in FIGIS to characterize fisheries management and its effectiveness: governance systems, monitoring indicators, management measures, scientific advice and related management actions, and the response of fisheries resources. As of December 2004, this inventory includes about half of the global coverage, with 1900 stocks and 2300 fisheries enumerated. The current status can be found at www.fao.org/figis/servlet/static?xml=STF_ proj.xml\&dom=org\&xp_nav=4, 2 .

Innovative information products conveying evolving knowledge. The FIGIS fact sheet, a fundamental FIGIS product, is a textual synthesis of information supported by tables, graphics and maps. Reached through the gateway pages, fact sheets are designed to present various characteristics within each broad fishery subject. Fact sheets implement the aforementioned system capacity; thanks to control exerted by a metadata level, they contain dynamically assembled information from various databases and present them in a homogenized and structured layout. Thus, in a controlled manner, fact sheets elaborate new knowledge while assembling information from previously disconnected and dispersed sources.

A species fact sheet includes the following features. A heading section presents the institutional data ownership together with the procedures, sources and methods used to compile the information. The cover page, together with the species scientific name, provides the title elements for web-page citations. The identification section consists of the species scientific name, together with other identification elements, such as image(s) of the species, and different official 
names and standard codes. The main section deals with a number of standard topics, including diagnostic features, habitat and biology, size, geographic distribution, interest to fisheries and conservation status. Finally, the sources and bibliographic section contains bibliographic references used/consulted to draw up the different parts of the fact sheet.

The core textual elements of the species fact sheet are provided by the SIDP program, often from information published in FAO catalogues, or specifically compiled and written by specialists, since the catalogues do not cover all important commercial groups.

One of the key features of fact sheets is the dynamic link to other databases; data, graphs, maps and links are seamlessly and dynamically assembled from other sources thanks to the different levels of interoperability possible with the FIGIS system. In the identification section, all the identification data elements (except images) are extracted on the fly from the Aquatic Sciences Fisheries Information System (ASFIS) database hosted in FIGIS. Thanks to an agreement with FishBase on interfacing databases using standard species codes, each paragraph of the fish species fact sheet links directly to the relevant data in FishBase and presents these data in a separate window. The same process applies to the links to CephBase for cephalopods and to the Information System for the Promotion of Aquaculture in the Mediterranean (SIPAM) for aquatic animals cultivated in the Mediterranean region. The species distribution map is dynamically generated from the GIS component of FIGIS. The interest to fisheries topic contains 1 or 2 statistical graphs (depending on whether the species is captured and/or cultivated) dynamically generated from the FAO global capture fishery and aquaculture statistics online database managed by FIGIS. It also links to dynamically generated lists of records from different domains (fishing techniques, fish stocks, fisheries, introduced species) indexed with this species. The bibliography section dynamically triggers requests to the FAO virtual library when reference is made to FAO publications. Similar dynamic queries will be directed in the near future to the Aquatic Sciences and Fisheries Abstracts (ASFA) database.

\section{FIGIS-ENABLING TOOLS AND MECHANISMS}

FIGIS technology. Designed as a 3-tier architecture web-based system, FIGIS is based on a relational database management system and open-source programming languages (Java, XML, XSL and HTML). As such, it is proprietary-free software and a platformindependent application. It also integrates a GIS component, allowing systematic data geo-referencing.
FIGIS is open to interoperability with external systems thanks to the adoption of international metadata standards, including Dublin Core, Agricultural Metadata Element Set (AGMES), Resource Description Framework Schema (RDFS), Ontology Web Language (OWL) and classifications of the International Standards Organization (ISO), the United Nations, the Coordinating Working Party on fishery statistics (CWP). This technology facilitates a flexible, scalable and distributed architecture, providing the ability to dynamically assemble data from distributed sources.

The metadata framework. Modules for marine resources, fisheries and other purposes (fishing techniques, management systems, etc.) are all new and complex information concepts. Handling these concepts consistently at the global level raises the challenge of coherent definitions, which is one of the purposes fulfilled by FIGIS metadata. Furthermore, FIGIS metadata provide a model for these complex concepts, based on elementary building blocks at the bottom of the information pyramid, such as aquatic species, gear type, vessel type, water area, or country, all of which use standard international classifications. Geographic entities included in the metadata are backed by a GIS component, thus enforcing systematic data georeferencing against standard, widely distributed GIS shape files. In utilizing this metadata standard framework, FIGIS ensures consistent and accurate links between the databases that are integrated to increase the value of the disseminated information. It also enables the dissemination of maps showing the location of stocks or fishery units, species distribution, or the spatial distribution of catch statistics.

Protocols for data sharing. Protocols implemented by FIGIS range from providing focused gateways to external systems such as FishBase, through dynamic and seamless assembly within FIGIS information pages located in partner systems, to the provision of content management system services. The latter include an upload service for registered users or systems willing to load their information in the FIGIS database from a range of formats (Excel, CSV, or XML files for statistical data, XML for metadata or textual information) and an online editing service for more simple direct inputs through HTML forms. Thanks to the metadata framework, data entry mechanisms exert tight control checks, verifying correct indexing over reference data. Here, the dream of information flow streamlining begins to become a reality.

Partnership arrangements. A key principle in developing FIGIS is to ensure that information is sustainable, quality-controlled, updated and provided by the most authoritative source. This is achieved through the development of partnerships which enable the sharing of information within a global network. The afore- 
mentioned global inventories of marine resources and fisheries provide the backbone of a Fishery Resources Monitoring System (FIRMS) currently being developed in close collaboration with regional fisheries organizations. FIRMS is a formal partnership arrangement adopted in February 2004 aiming at the systematic assembly of quality-controlled information on status and trends of fishery resources. It currently involves 8 regional fishery organizations willing to contribute information to the system according to their own mandates.

\section{ISSUES RAISED BY THE GLOBAL INTERNET UNDERTAKING}

Diversity of definitions/views worldwide. The challenge of harmonizing stocks or fisheries status reports worldwide lies in the ability to propose acceptable definitions and topic trees to all participating institutions. When one asks 'What is a fishery?', the global community gives numerous responses and definitions. This variability is principally a question of scale (which aggregation level is being considered?), coupled with the disciplinary angle used when defining a fishery. In acknowledgement of the most frequent approaches to fisheries analysis and reporting, the retained definition emphasizes that the fisheries concept stresses the usage and management perspective of fishery resources. According to the FIGIS definition, extending that of the FAO Fisheries Glossary (http://fao.org/ fi/glossary), 'a fishery is an activity leading to harvesting fish within the boundaries of a defined area; the fishery concept fundamentally gathers indication of human fishing activity including from the management, biological/environmental and technological view points'.

Towards more complex requirements. Integrating more databases means facing additional requirements. The records in the introduced species database not only include references to standard species, but also to subspecies, strains, or hybrids. In contrast, many fisheries databases refer to species groups, or to species using common local names. The emerging demand for traceability of fishery products against their environment of origin implies the ability to develop and manage systematic lists of geo-referenced environments. Enabling consistent cross-referencing on species or geographic components on a global level requires major effort and close coordination.

An immense potential to handle carefully. Assembling information from heterogeneous databases presents immense processing and modeling challenges. Original sources are compiled in different contexts, following distinct methodologies and referring to dif- ferent terminologies or definitions. Enabling searches on integrated sources for selective extraction of information or applying algorithms generating summary indicators may produce misleading knowledge by presenting parts of the original information out of context. This is where frameworks on information sharing policy, agreed upon by stakeholders, will play an increasingly important role in the near future.

\section{DISCUSSION AND CONCLUSIONS}

Species identification work in the FAO has essentially been aimed at improving fisheries statistics. Gaps in publication for many regions or taxonomic groups still remain. (1) No guides exist for FAO Fishing Areas 41 and 87 (South America), which correspond to important fishing zones and developing countries for which no other regional guides are available. (2) Very important taxonomic groups, from a fisheries point of view, are not yet covered by FAO catalogues, e.g. batoids, flatfishes, sparids and carangids. (3) A database on crustaceans is needed, though some information on crustaceans is already available in FIGIS and other sources. (4) There is a need for information on noncommercial taxonomic entities that may have an impact on, or be impacted by, fisheries (jellyfish, corals, etc.).

Fisheries science requires taxonomic stability for the well-known species and quick taxonomic updating for new target species or species affecting fisheries in some way. Newly exploited species, such as those exploited on seamounts, or species groups, such as sharks, for which the conservation status changes to endangered require guides for accurate short-notice identification.

The requirements for species identification have changed. The greater challenge posed by the poor state of world fishery resources brings with it an ever broadening need for information. The multifaceted fisheries approach of the FAO constitutes a response whereby aquatic species information occupies a crucial position: species are targets of fishing techniques; species define key dynamic population features of fishery resources and stocks; and species determine the structure of biogeographic components of multispecies fisheries. High-quality quantitative and qualitative reporting requires accurate taxonomic identification and the availability of a thesaurus of vernacular names in multiple languages for species and species groups, as well as ways to connect scientific names to vernacular names.

Progressive implementation of the ecosystem approach to fisheries management leads to emerging needs that can be categorized into 3 groups: (1) analy- 
sis of trophic relationships, which requires the ability to identify species from parts of organisms, such as otoliths, scales, or parts of crustacean carapaces, etc.; (2) libraries for ecological modeling parameters; and (3) synthetic products from ecological modeling, such as biodiversity indicators in multispecies assemblages, faunistic changes, or identification of ecosystem units. Faunistic changes, such as anthropogenic species introductions, or variations in the distribution area due to climatic changes, should be rapidly recorded in the databases. The Mediterranean and Black Sea, with the effects of Lessepsian species, tropicalization (Quignard \& Tomasini 2000) and water-ballast introductions with the dramatic consequences they have for fisheries, such as the ctenophore Mnemiopsis leidyi (Zaitsev \& Öztürk 2001), is an illustration of this need. The CIESM atlas of exotic species is a significant contribution in this regard (Galil et al. 2002, Golani et al. 2002, Zenetos et al. 2003).

The needs identified are immense, and the Internet opens new but challenging horizons. Internet technologies are certainly a way to 'reinvent' taxonomy (Gewin 2002, Godfray 2002), and one question could be 'Are all of these databases redundant?' or, more importantly, 'Are there any taxonomic groups absent from the Internet?' The main issue is certainly how to optimize world community efforts to generate and share taxonomically related knowledge in a global network and, consequently, how to construct globally accessible knowledge. The FIGIS experience of a webbased system integrating knowledge from distributed web resources shows that the key to success is to adopt international metadata standards and forge agreements on authoritative lists, classifications and coding systems. The greatest challenge related to this approach is the ability of the various interconnected databases to share compatible semantics. This is further complicated by the fact that the adoption of metadata standards is usually discussed within communities of similar interest, and the need to interrelate metadata standards among dissimilar communities sharing a few common dimensions remains a major challenge. Ongoing research efforts are being coordinated by the FAO to demonstrate how ontological methodologies may provide responses to this issue and enhance semantic interoperability in fishery information systems (Gangemi et al. 2004). Globally, the role of each party has to be clearly defined according to the party's mandate. FIGIS, supporting FAO's efforts to promote sustainable and responsible use of fishery resources, offers the biogeographic community Internet services that are directly related to the FAO's institutional role. Web services are available to clients for dynamic re-

Editorial responsibility: Howard I. Browman (Associate Editor-in-Chief), Storebø, Norway trieval of international classifications and of reference lists maintained by the FAO, or of XML-based products, such as species fact sheets or fishery statistics.

Acknowledgements. The authors are very grateful to Mr. L. Garibaldi for his comments and advice on catch statistics, and to Mr. F. Carocci for providing the cartography.

\section{LITERATURE CITED}

Boero F (2001) Light after dark: the partnership for enhancing expertise in taxonomy. Trends Ecol Evol 16(5):266

Caddy J, Garibaldi L (2000) Apparent changes in the trophic composition of world marine harvest: the perspective from FAO capture database. Ocean Coast Manag 43:615-655

CECAF (Committee of the Eastern Central Atlantic Fisheries) (2004) Regional implementation of the strategy for improving information on status and trends of capture fisheries. In: Report of the 17th session of the Fishery Committee for the Eastern Central Atlantic. Dakar, Senegal, 24-27 May 2004. FAO Fisheries Report No. 754, FAO, Rome

FAO (Food and Agricultural Organization) (1995) Code of conduct for responsible fisheries. FAO, Rome

FAO (Food and Agricultural Organization) (2004) FAO yearbook fishery statistics. Capture production 2002. FAO Fisheries Series No. 66, FAO Statistics Series No. 180, Vol 94/1 2002. FAO, Rome

FAO (Food and Agricultural Organization) (2005) Review of the state of world marine fishery resources. FAO Fisheries Technical Paper No. 457, FAO, Rome

Fischer W (ed) (1973) Mediterranean and Black Sea (Fishing Area 37). FAO species identification sheets for fishery purposes. FAO, Rome

Galil B, Froglia C, Noël P (2002) Crustaceans: decapods and stomatopods. In: Briand F (ed) CIESM atlas of exotic species. 2. CIESM Publishers, Monaco

Gangemi A, Fisseha F, Keizer J, Pettman I, Taconet M (2004) A core ontology of fishery and its use in the fishery ontology service project. In: Gangemi A, Borgo S (eds) First International workshop on core ontologies. EKAW Conference CEUR-WS, Vol 118. Available at http://sunsite.informatik.rwth-aachen.de/Publications/

Gewin V (2002) All living things, online. Nature 418:362-363

Godfray HCJ (2002) Challenges for taxonomy. The discipline will have to reinvent itself if it is to survive and flourish. Nature 417:17-19

Golani D, Orsi-Relini L, Massutí E, Quignard JP (2002) Fishes. In: Briand F (ed) CIESM atlas of exotic species. 1. CIESM Publishers, Monaco

Myers RA, Worm B (2003) Rapid worldwide depletion of predatory fish communities. Nature 423:280-283

Pauly D, Alder J, Bennett E, Christensen V, Tyedmers P, Watson R (2003) The future for fisheries. Science 302: 1359-1361

Quignard JP, Tomasini JA (2000) Mediterranean fish biodiversity. Biol Mar Mediterr 7(3):1-66

Zaitsev Y, Öztürk B (eds) (2001) Exotic species in the Aegean, Marmara, Black, Azov and Caspian Seas. Turkish Marine Research Foundation, Istanbul

Zenetos A, Gofas S, Russo G, Templado J (2003) Molluscs. In: Briand F (ed) CIESM atlas of exotic species. 3. CIESM Publishers, Monaco

Submitted: January 14, 2005; Accepted: December 15, 2005 Proofs received from author(s): May 24, 2006 